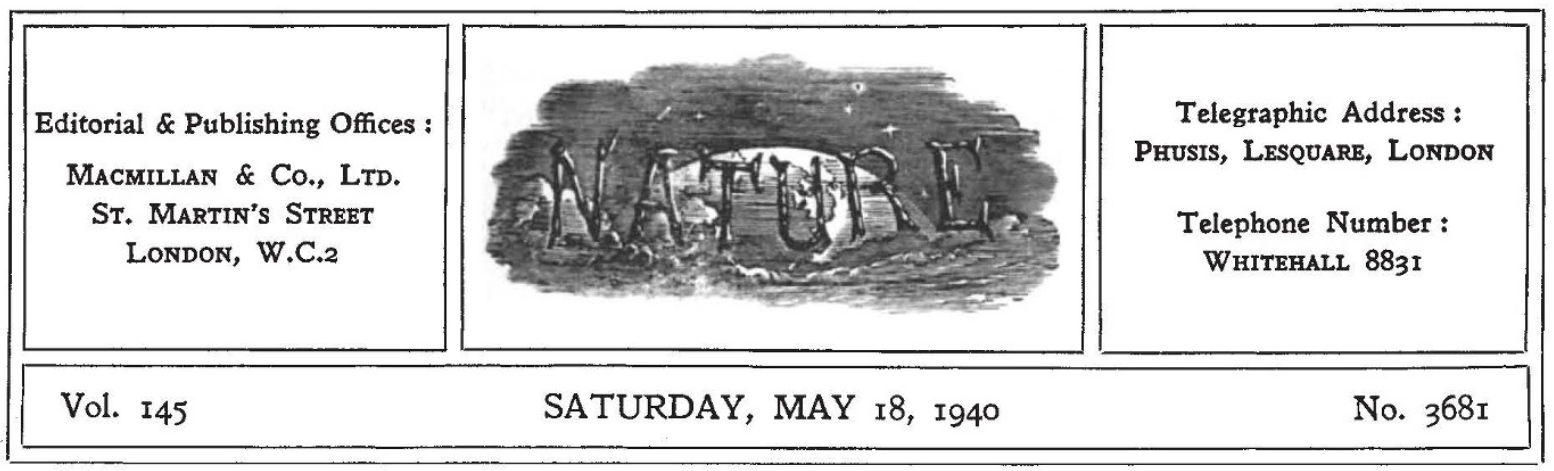

\title{
CULTURAL RELATIONS OF FRANCE AND BRITAIN
}

$\mathrm{T}$ HE cause for which NATURE stands, the disinterested pursuit of scientific inquiry, cannot recognize distinction of race, creed, language or nationality. Wherever the truly scientific spirit is at work, labourers in the intellectual field recognize one another as men and brethren; and this is still the case, even in the distracted times in which we live. But here a tragic picture presents itself. What we have called the truly scientific spirit is wholly or partly quenched as soon as the lamp of freedom is extinguished. Freedom of thought and expression had been gained at a great price, and after centuries of persecution, in the chief civilized countries of the world. It has been temporarily lost in certain of the traditional and most influential homes of scientific and philosophic culture. In the words of M. Edouard Herriot, the dictators have killed in their countries the spirit of freedom and the idea of human dignity.

It falls, therefore, to the great democratic nations to uphold the banner of freedom. If they are to do so effectively, it must be through a deeper mutual understanding; and in the long run such a result is really a question of education. It is essentially for that reason that steps have recently been taken by the responsible Ministries in Great Britain and in France to promote a sympathetic understanding of each other's aims and ideals in all educational institutions, and among all branches of the teaching profession, primary, secondary and university. In Great Britain it becomes one of our definite purposes to try to comprehend and appreciate the cultural position of our great ally.

At the close of the War of 1914-18, the general educational position in France closely resembled the position in Great Britain at the beginning of the century. After our Act of 1902, elementary schools nolonger formed a water-tight compartment, having no connexion with secondary schools. But similar conditions remained unchallenged in France another dozen years or more. A French child of six entered either the local elementary school or the preparatory department of the lycée. The former was free, but the latter was not, and so at the age of six the educational destiny of the child was fixed, and depended upon the ability of his parents to pay fees. The vast majority of the children of France passed through the elementary schools until the age of thirteen, a small proportion remained for advanced courses, and a very few obtained scholarships at the lycée at the age of twelve. The barrier of class and wealth divided the elementary and secondary systems. The fortunate children (about one in ten) who entered preparatory departments at six proceeded at ten or eleven to the lycée proper, and at about seventeen took the baccelauréat, which gave access to the universities and other places of higher education. The lycées provided courses in classics, modern studies, and pure science, and were not vocational in any sense. Elementary and secondary teachers knew as little of each other as if they inhabited different countries. A queer sort of democracy, the reader may say; however, like our own, it was and it is a democracy with a past.

But a profound educational stir took place during the last War and it is said that the idea of the far-reaching reform known as l'école unique was conceived by a group of officers in the trenches on the Western Front in 1917-18. Equal opportunities for all children, without regard to the means of their parents, was the fundamental feature of the reformers' demands. Sympathy and support came from many influential quarters, but 
long-established traditions die hard, and root-andbranch reform could not come quickly. For some years after the conclusion of the War the discussion was vigorously continued, and in 1927 a definite scheme was published, taking the form of a parliamentary Bill. It was this scheme which substantially became the law of the land in 1937, when M. Jean Zay was Minister for Education in the Popular Front Government.

The details of the new law, the operation of which is inevitably slowed down by the outbreak of the present War, can here be only briefly summarized. Similar courses of instruction are provided in all schools for children between six and twelve. At the latter age, tests are applied which determine whether a child continues his primary course to a higher stage or starts upon a secondary course. In the latter event he enters the classe d'orientation for a year, during which the kind of further education for which he is best fitted is settled. This classe d'orientation is from the point of view of British teachers the most remarkable feature of the system, and its working will no doubt be carefully watched, now that opportunities of exchange of duties with French teachers are being increased. In France itself the innovation has been subjected to adverse criticism, but the experiment is being very carefully conducted. This introductory year having been completed, the pupil enters upon a course either in classical or in modern or in technical humanities, the differences between the three being gradually made by increasing emphasis in one of the three directions. The gradual abolition of fees in the case of students who reach scholarship standard brings within sight in France what Mr. Harold Nicolson, M.P., in a recent broadcast talk, has advocated for England-a classless education.

From the point of view of Nature, perhaps the most interesting and important thing yet remains to be said. Throughout his course, it will be observed, the pupil is engaged upon the humanities, with gradually increasing stress upon the classical or modern or technical side-but always the humanities. In Anglo-Saxon countries, specialization may be carried so far that from a too early age a boy devotes himself so much to what may be found inside a laboratory that, unless his home opportunities are uncommonly good, he may develop into something which one hesitates to call an educated man. From that position the French tradition of general culture is a safeguard. The more one studies the history of educational changes and controversies in France, the more deeply impressed one becomes by the steadfast adherence of the French mind to that tradition. For three centuries, including the Revolution, the Napoleonic era and the Restoration, the old classical tradition remained intact, partly to secure secondary education as a privilege for the upper and middle classes, but partly also because nothing satisfactory was found to take its place. A change was bound to come, as Matthew Arnold foresaw in 1865 , but it came slowly. The legacy left by the classical tradition is seen in the continued determination that French culture, which led the way in Europe for centuries, shall be preserved. To quote Prof. Kandel, an American authority on comparative education, it is through "études désintéressées" (general studies), that French secondary education "aims to cultivate judgment, taste, appreciation, and an ability to think clearly and logically. . . More concretely expressed, the measure of a sound liberal education is the ability to speak well and to write well, as the outward indication of clear thinking".

More recently, Prof. Kandel has, in his capacity as editor of the 1939 report of the International Institute, Teachers College, Columbia University, brought together two statements by distinguished Frenchmen on the meaning of a liberal education in France in the twentieth century. One of these authorities, the Director of the École Normale Supérieure, though making concessions to the modernists, ends by declaring that the advocates of a liberal education based on a general classical culture, if they must yield any territory, will put up a fierce resistance, relying on a tradition of which France is proud. The other, a professor at the Lycée de Versailles, and general secretary of Les Compagnons de l'Université Nouvelle, equally maintains that a liberal education should subordinate the acquisition of knowledge to the task of so educating the mind as to enable it to attain to as broad and deep a culture as possible. But he denounces the exclusively literary tradition as exhibiting a blind faith in a single ideal supposed to lie beyond discussion. He charges the advocates of that tradition with showing profound ignorance of the vast extensions of the human spirit as a result of the development of experimental sciences since the sixteenth century, and with slighting "the remarkable educative value of the use of the experimental methods for intellectual training". We think the flowing tide is with the modernists. 
There, however, we must leave the matter, trusting to have said enough to suggest the immense importance of supplementing the defensive and economic relations of Great Britain and France by a better understanding than ever before of the educational aims and aspirations of the two countries. As M. Sarraut has recently said to the educational leaders of France, the spirit of sympathy and cordiality for the people of the Allied countries must be created among all young people from school children to university students. There can, he wisely added, be no question of exercising any pressure in influencing their minds. Neither familiarity nor affection can be imposed. But we can prepare the ground which favours their development, and this is less perhaps a matter of direct teaching than of providing opportunities of bringing about an intuitive understanding.

\section{A GREAT PSYCHOLOGIST OF SEX}

My Life

By Havelock Ellis. Pp. xviii $+542+8$ plates. (London and Toronto: William Heinemann, Ltd., 1940.) 15s. net.

$\mathrm{H}^{\mathrm{H}}$ ERE we have the life-story of one who, with many other literary and cultural achievements to his credit, will be known above all as the man who made it his chief work to bring sanity into the sphere of sex and to remove those taboos which had hitherto kept sex so largely outside the pale of impartial scientific thought. This autobiography is no mere product of the author's declining days ; it is the fulfilment of a project formed in early life, a project that, like all his other enterprises, came slowly but steadily to fruition, being written at what he judged to be the most favourable moments from the age of forty onwards. Ellis indeed held autobiography in high esteem; it was his view that "of all forms of prose, outside the limits of imaginative art, there is no other form so precious in its nature and so permanent in its value". There can be little doubt that the book does well and truly fulfil its author's purpose. Although it is unlikely that it will ever be considered one of the world's very few imperishable monuments of self revelation, it yet provides a sympathetic and illuminating picture of a delicate, sensitive and philosophic being, who was willing to accept himself with the capacities and limitations that Nature had provided, and who understood well how to reconcile himself to his limitations and to make the most of his capacities-a task that few accomplish with so good a grace and in such ample measure.

More than half of the book is concerned with the years of his marriage, and this provides a fascinating study of the long union of two very dissimilar personalities-the retiring, methodical, introvert Havelock, and the gifted but tempestuous extravert Edith (née Lees) who was his wife-a union further complicated by the existence of a strong homosexual tendency in the latter partner, though at the same time one that was firmly cemented by a deep personal affection and a lively common concern for the welfare and progress of humanity. With the death of Mrs. Ellis in 1916 (after an illness that affected both her mental and her physical health) the detailed story ends, and but a few pages are devoted to the remaining twenty-three years of his life. His marriage ended and his major self-appointed task accomplished (the last of the six original volumes of the "Studies in the Psychology of Sex" was completed in 1910, though a supplementary seventh volume appeared in 1928), he felt he had drunk deeply of the well of life and could afford to enjoy in relative tranquillity such years as yet remained. These years, filled with loving companionship, with tender memories, and with the sense of a task well accomplished and in its outcome successful beyond all expectation, were very happy ones, and the book ends on a note of optimism that nowadays is rarely to be met with. In an age in which we are beginning to look back with nostalgic longing to the calm days of the later nineteenth century, it is cheering and refreshing to realize that, in the eyes of one who lived and strove in those days, our modern world, for all its insecurity and manifest disorder, holds many compensations-compensations which to Ellis were the greater in as much as he felt that he himself had contributed to their existence.

Many readers will regret that the book does not deal more fully with the author's intellectual development and the emotional factors underlying it. We are, it is true, told how, as a young man of about twenty, he had already dimly formed the project which afterwards found fulfilment in his magnum opus. Looking back some fifty years he 